\title{
EVALUATION OF "TENT-POLE" GRAFTING TECHNIQUE FOR RECONSTRUCTION OF MANDIBULAR RIDGE VERTICAL DEFECTS (CLINICAL AND RADIOGRAPHIC STUDY)
}

\author{
Asmaa M. Abd El fattah ${ }^{1 *} B D S$, Abd El Aziz F. Khalil ${ }^{2} P h D$, Lydia N. Melek ${ }^{3} P h D$.
}

\section{ABSTRACT}

INTRODUCTION: Continuous residual ridge resorption is seen after tooth loss. In addition, it is not possible to place an implant without bone regeneration after loss of the adequate bone height. Numerous techniques have been mentioned for reconstruction of the atrophic mandibular ridge. Tenting of the soft tissue matrix allow maintaining space for the graft material for vertical ridge augmentation.

OBJECTIVES: The aim of this study is to evaluate clinically and radiographically the efficiency of "Tent- Pole" grafting using titanium mini-screws with guided bone regeneration for augmentation of mandibular ridge vertical defects.

MATERIALS AND METHODS: Twelve patients with posterior mandibular defects were treated with guided bone regeneration around titanium screws that tent out the soft tissue matrix with an age range of 43 and 60 years. They were of both sexes (4 males and 8 females). Osteosynthesis miniscrews were fixed on the alveolar ridge with an average of 2-3 mm of their length exposed, alloplastic material surrounded the screws completely and a resorbable membrane is used for the guided bone regeneration.

RESULTS: The mean bone height value after six months was found to be statistically significant with the mean bone height value preoperatively and immediate post operative $(\mathrm{p}<0.001)$. Also, there was statistically significant difference in the mean bone density between the six months post operative and immediate post operative values $(\mathrm{p}<0.001)$.

CONCLUSION: From the results of this study, the screw tent -pole grafting technique with guided bone regeneration is a technique of high reliability in restoring mandibular vertical bone loss.

KEYWORDS: Tent-pole, guided bone regeneration (GBR), mandibular defect.

RUNNING TITLE: Screw Tent-Pole grafting for mandibular ridge vertical defects.

1 BDS, 2014, Faculty of Dentistry, Alexandria University, Egypt.

3 Assistant professor of Oral and Maxillofacial Surgery, Department of Oral and Maxillofacial Surgery Faculty of Dentistry, Alexandria University, Egypt.

* Corresponding Author: E-mail: asmaa92m7amed@gmail.com

\section{INTRODUCTION}

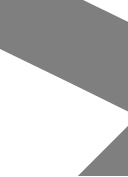

Regardless of the progress of modern dentistry, tooth extraction leads to severe difficulties and impairment of the masticatory or chewing system and is believed to be a very complex issue for both the dentist and the patient. Loss of teeth leads to poor dietary habits and worsening of quality of life. Permanent teeth are extracted for some reasons including tooth decay, periodontal disease, traumatic -injuries, impacted teeth, unsuccessful dental procedures (root canal treatments, etc.) (1).

The alveolar ridge shows dramatic changes in height and width after tooth loss. This necessitates using augmentation procedures to achieve optimal results and long-term survival of the prosthesis (2). Moreover, vertical alveolar bone loss constitutes a major challenge in partially edentulous patients. Various procedures, for example, onlay bone graft, guided bone regeneration, distraction osteogenesis, and ridge osteotomies have been described $(3,4)$. However, no single augmentation procedure delivered evidence-based criteria to be generalized in the clinical setting.

Tenting of periosteum and soft tissue has shown good potential in the rehabilitation of atrophied alveolar ridges. Expansion of the soft tissue with the use of titanium mini-screws and guided bone regeneration was introduced by Bash Le et al., 2010 (5). They evaluated "the use of titanium screws in tenting fashion that was surrounded by particulate human mineralized allograft to reconstruct large vertical mandibular defects before implant placement". Fifteen patients with large vertical defects $(\leq 7 \mathrm{~mm}$ of residual height) were clinically evaluated 4 to 5 months after augmentation for implant placement and harvesting bone cores for histological evaluation. The mean increase in the bone height was $9.7 \mathrm{~mm}$ (5).

Alloplastic bone materials as resorbable ceramics act like a scaffold or temporary space fillers that allow for new tissue to develop. The resorption of these bone substitutes is essential as they are eventually to be replaced by newly formed bone (6). The distinctive structure of NanoBone ${ }^{\circledR}$ (a combination of nanocrystalline hydroxyapatite and highly porous silica gel) results in quick bone formation. Using NanoBone ${ }^{\circledR}$ can considerably decrease the whole treatment period (7). 
Platelet Rich Fibrin (PRF) has a natural fibrin framework with growth factors within it that could stimulate tissue regeneration efficiently. So, when it was combined with the graft material, higher osteoconductive capacity is achieved. Moreover, PRF has a rapid degradability within 14 days $(8,9)$.

A predictable intraoral guided bone regeneration (GBR) concept was established in the late 1980s and early1990s $(10,11)$. Different kinds of resorbable and non resorbable membranes have been utilized in the GBR procedures. The use of occlusive barrier membranes adds stability to the graft and minimizes its mobility, promotes the ingrowth of cells with osteogenic properties and prevents immigration of cells from the overlying soft tissues. Hypro-Sorb ${ }^{\circledR} F$ is a rigid, bilayer membrane that is absorbable, bovine and sterile atelo-collagen type 1 (12).

So, the objective of this study is to assess clinically and radiographically the effectiveness of "Tent-Pole" grafting technique using titanium mini-screws with guided bone regeneration for augmentation of mandibular ridge vertical defects.

The null hypothesis of this study is that there is no significant difference in the alveolar ridge height in the clinical and radiographic parameters after reconstruction of vertical mandibular ridge defects with screw tent pole grafting technique and guided bone regeneration.

\section{MATERIALS AND METHODS}

Study design: Twelve patients with vertical defect or saucer shaped depression in the posterior mandibular ridge. They were treated with guided bone regeneration around titanium screws that tent out the soft tissue matrix.

Study sample: Patients were recruited from the outpatient clinic of the Oral and Maxillofacial Surgery Department, Faculty of Dentistry, Alexandria University, Alexandria. Sample size estimation: A minimal total sample size of twelve patients with mandibular resorbed edentulous ridge is needed to detect an assumed significant difference in the alveolar ridge after the reconstruction procedure with common estimated group standard deviations of $1 \mathrm{~mm}$ and with 95\% confidence level and $80 \%$ power using One-sample t test. (PASS program version 20) (13).

Procedures were done in accordance with Ethic research committee, Faculty of Dentistry, Alexandria University.

\section{Eligibility Criteria's}

Patients were chosen according to some criteria: Patients of both sexes in the age frame between 40 and 60 years old. Patients with missing lower tooth or teeth and having a related large vertical bony defect, $7 \mathrm{~mm}$ residual bone height (from the crest of the ridge to the inferior alveolar nerve) and requiring about $5 \mathrm{~mm}$ rise in the vertical height of the mandibular alveolar ridge for future prosthetic rehabilitation, in addition, Patients were required to have an acceptable oral hygiene and a desire to enhance it

Exclusion criteria: Presence of infection or local lesions, parafunctional habits, current chemotherapy or radiotherapy, heavy smoking. Alcohol or drug abuse and medically compromised patients with diseases that affect passively the clinical procedure or result.

The purpose of this study, the procedures, benefits and the expected complications were illustrated for all the patients.
Moreover, every patient signed a consent about this and informed that they had the right to withdraw whenever they want.

\section{Materials}

1. Osteosynthesis mini screws (Antonhib, Germany)

Self-tapping mini screws made of titanium with their width $2.0 \mathrm{~mm}$ and their length comes in 7,9 $\mathrm{mm}$.

2. Synthetic bone graft (ARTOSS GmbH, Germany)

NanoBone ${ }^{\circledR}$ granulate $0,6 \mathrm{ml}$ formed in the ratio of $76 \%$ Hydroxylapatite and $24 \%$ Silica. It is totally alloplastic material with no animal or human elements. The interconnecting nanopores supply space for vascularization and bone regeneration.

(Figure .1,A)

\section{Hypro-Sorb $\AA^{\text {F }}$ (Bioimplon GmH. Germany)}

Hypro-Sorb® F membrane is a rigid, absorbable, bovine, sterile atelo-collagen (99.9\% collagen type I without telopeptides). It is a double-layered structure with one smooth side toward the soft tissue and another rough side toward the bone. The membrane was fixed with bone tacks

$3.5 \mathrm{~mm}$. (MCT,USA). (Figure.1,B)

4. Platelet rich fibrin (PRF). (Figure.2)

\section{Procedures}

\section{Preoperative evaluation}

1. History

2. Clinical examination

Extra oral and intraoral examination were done (14).

3. Radiographic examination

Cone beam computed tomography (CBCT) was done to assess the pre-operative bone height.

\section{Surgical procedure}

All the procedures were performed under local anesthesia. Chlorhexidine gluconate $0.12 \%$ (Hexitol: the Arab Drug Company, Cairo, A.R) was used for oral cavity preparation. Mid-crestal incision with vertical releasing incision was done down to the bone with blade no.15, the bone surface was exposed after reflection of the mucoperiosteal flap with the periosteal elevator. (Figure.3, A) Buccal and lingual tissue releases were done before screw or graft placement to ensure tension-free closure through split thickness dissection and supraperiosteal advancement. Fixation of the screws over the alveolar ridge was done, so that about $3-5 \mathrm{~mm}$ of the screw length exposed. Decortication (perforation of the outer cortex) was done with a rounded bur to increase future vascularization of the graft. The collagen membrane was fixed lingual to the defect. (Figure.3, B) Bone graft material was introduced and adapted to cover the screws completely; the defect was overcorrected with particulate material in expectation of future graft resorption. (Figure.4)

PRF was prepared in a table centrifuge machine at 3000 revolutions per minute (rpm) for 10 minutes. After separation of PRF, it was prepared like a membrane by compression device and then placed on top of the grafting material as a source of growth factors (9).

Then the collagen membrane was rolled, adjusted over the grafted site and fixed on the buccal side with bone tacks. (Figure.5) Flap repositioning and closure by horizontal mattress sutures using 4.0 vicryl suturing material (Ethicon, Edinburgh). 

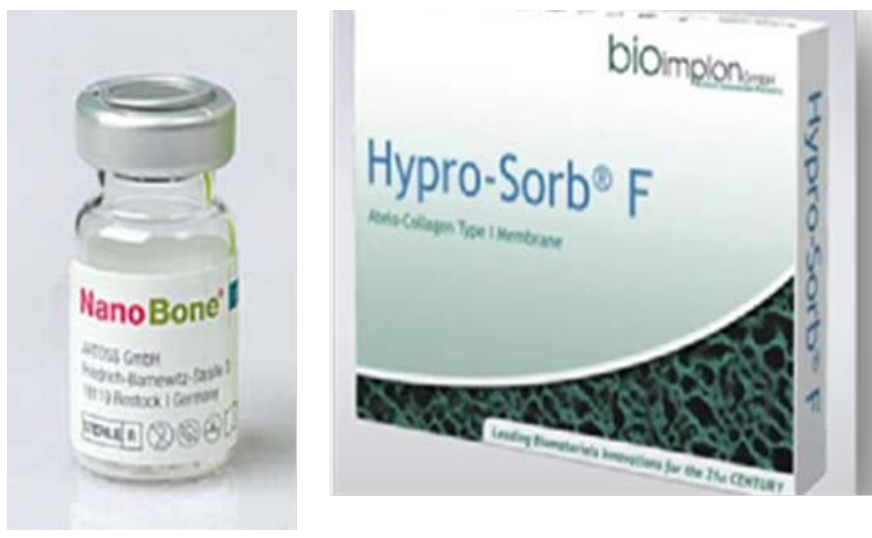

Figure (1):A) A photograph showing NanoBone ${ }^{\circledR}$ graft .B)Hyprosorb ${ }^{\circledR}$ F Atelo collagen type 1 membrane .

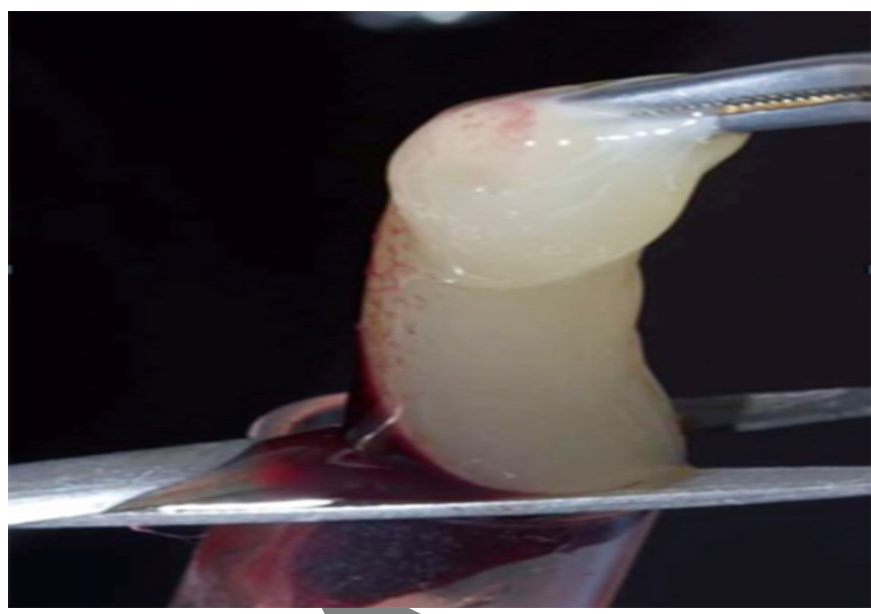

Figure (2): A photograph showing PRF after preparation.

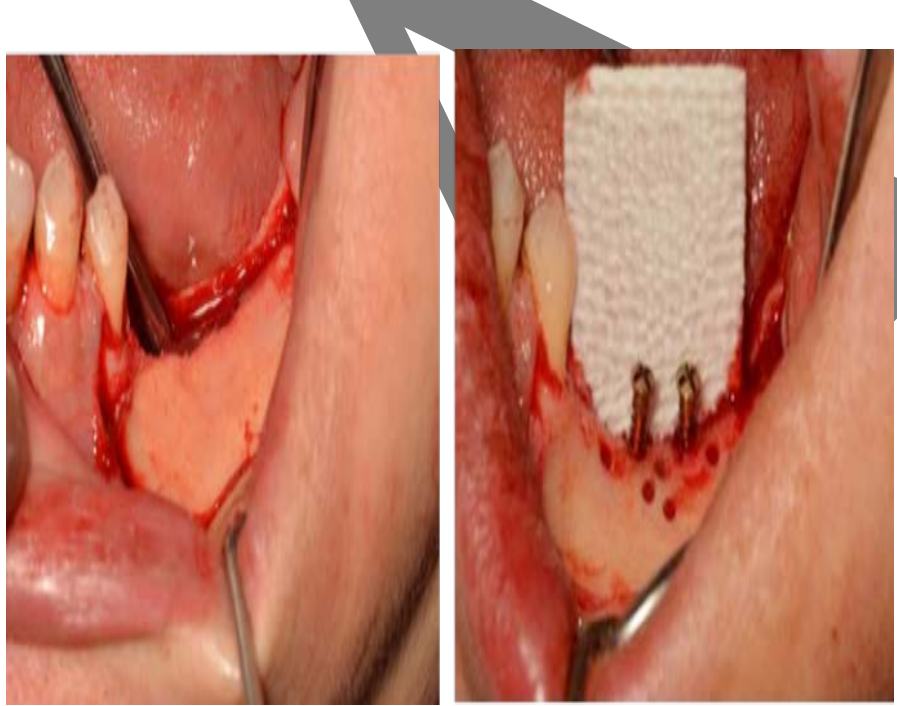

Figure (3): A) A photograph showing the bony defect after retraction of mucoperiosteal flap.B) Aphotograph showing two mini screws"tent poles", collagen membrane fixed on the lingual side

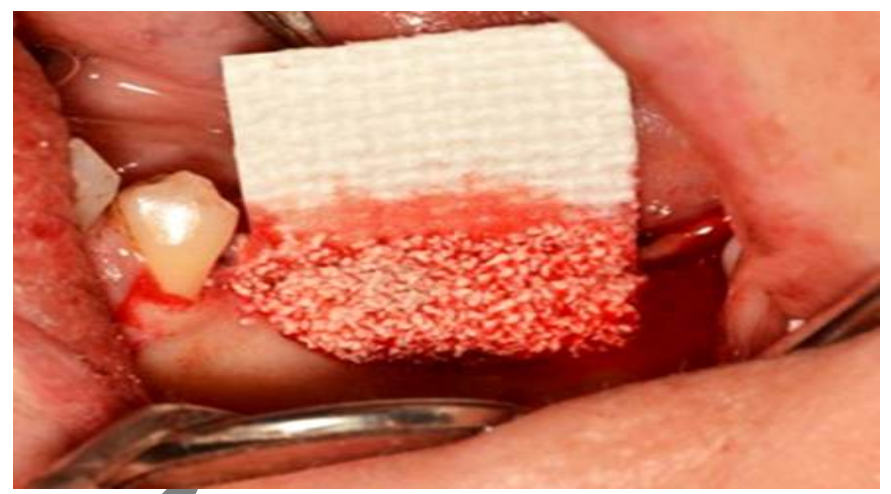

Figure (4):: A photograph showing grafting material covered the screw heads completely.

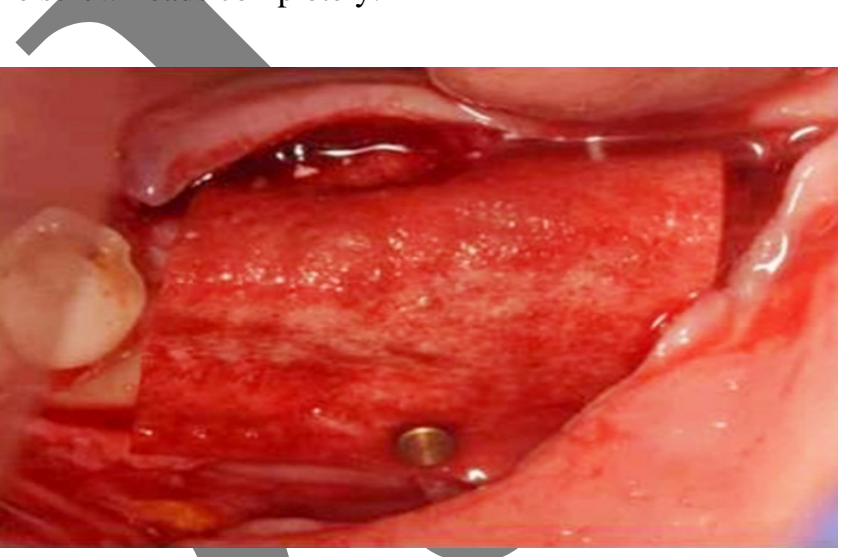

Figure (5): A photograph showing collagen membrane fixed on the buccal side with bone tacks

\section{Postoperative medication}

Extraoral cold fomentations every one hour during the first 24 hours and instructions to maintain the oral hygiene. Also, medications were prescribed including:

- Antibiotic 1gm twice daily for 5 days. Augmentin: (Amoxicillin clavulanate) GlaxoSmithKline, UK.

- Nonsteroidal anti-inflammatory drug three times daily for 5 days. Cataflam 50mg (Diclofenac Potassium): Novartis-

\section{Switzerland.}

- Antiseptic mouthwash for 1 week starting from the second day. Hexitol (Chlorhexidine): Arabic drug company, ADCO.

\section{Follow up phase}

Patients were clinically evaluated after 24 hours, 7days and 14 days for pain, edema and wound healing.

\section{Radiographic evaluation}

Postoperatively, Cone Beam Computerized Tomography (CBCT) was done immediately during the first week and after six months to evaluate both the increase in vertical ridge height and bone density.

OnDemand3D ${ }^{\mathrm{TM}}$ software (Cybermed Inc.) was used to assess vertical height. Measurements were taken as follows: From the alveolar crest till the inferior alveolar nerve, the vertical bone height was measured from the cross-sectional views of the pre operative, immediate post-operative and 6 months postoperative CBCT. Bone density was estimated radiographically using the same software.For measurements in the gray density values, voxel values (VV) in CBCT , the desired area (between the 2 mini screws) was selected and the average density was chosen. 


\section{Statistical analysis of the data}

All the obtained data was statistically analysed and presented in tables, graphs and charts using the IBM Statistical Package for Social Science (SPSS) ${ }^{*}$ version 20 (13). Number and percent were used to describe qualitative data. The normality of distribution was confirmed using the KolmogorovSmirnov test. Range, mean, median and standard deviation were used to describe the quantitative data. The level of significance was at 5\%. ANOVA with repeated measures and Paired T-test were used for the normally distributed quantitative data and to compare between more than two periods.

\section{RESULTS}

Twelve patients with residual ridge atrophy in the posterior mandible were treated with guided bone regeneration around titanium screws that act as a "Tent Poles" and maintain a space for the graft material. They were from 43 to 59 years old with a mean age of $(52.08 \pm 5.84)$. They were of both sexes ( 4 males and 8 females). The ratio between males and females was 1:2. Clinical and radiographic follow up was done for 6 months.

\section{Clinical evaluation}

1. Pain

Pain was evaluated immediately after 24 hours after surgery, 7days and 14 days to detect any pain according to a visual analogue scale (VAS) $(0-10)$ where $0=$ no pain and $10=$ worst pain (15).

For all patients moderate to intense pain at the surgical field was detected after 24 hours of the surgical procedure with a lowest value of 6.0 and a highest value of 10.0 and a mean value of $(8.00 \pm 1.60)$ at the first week postoperatively the minimum pain value was 2.0 and the maximum was 6.0 with a mean value of $(3.50 \pm 1.51)$. All patients had mild pain by the second week with the lowest value of 1.0 and the highest value of 2.0 with a mean recorded value of $(1.17 \pm 0.39)$.

\section{Edema}

It was assessed by its capability to pit (16). Follow-up was done after 24-hours, 7 days and 14 days. The pitting was graded as follows:

- +1 (trace) insignificant indentation rapid returns to normal.

- $\quad+2$ (mild) the indentation returns to normal in few seconds.

- $\quad+3$ (moderate) $6 \mathrm{~mm}$ indentation rebounds in 10-20 seconds.

- $\quad+4$ (sever) $8 \mathrm{~mm}$ indentation rebounds in more than 30 seconds.

All patients showed edema with a minimum recorded value at the first postoperatively day of 3.0 and a maximum value of 4.0, which reduced at the first week to be with the lowest value of 1.0 and the highest value of 2.0. Edema nearly receded in the second week postoperatively to be with a minimum and maximum value of 1.0 .

\section{Wound healing complications}

Within two weeks after surgery, four cases were with incomplete wound healing (wound dehiscence), screw heads were exposed in two cases and there was loss of the graft in the other two cases. Eight cases were with complete wound healing. There was no infection for all the patients through the follow-up phase (Table 1).

\section{Radiographic evaluation}

\section{a. CBCT for measurement of bone height}

CBCT was used to assess the increase in vertical bone height above the inferior alveolar canal that was evaluated preoperatively, immediate postoperative and after 6 months. (Figure.6)

Alexandria Dental Journal. Volume 46 Issue 1 Section A
Table (1): Distribution of the studied cases according to complications $(\mathrm{n}=12)$

\begin{tabular}{|l|c|c|}
\hline \multicolumn{1}{|c|}{ Complication } & No. & \% \\
\hline Patients with no complications & $\mathbf{8}$ & $\mathbf{6 6 . 6 7}$ \\
\hline $\begin{array}{l}\text { Patients with (partial dehiscence) screw head } \\
\text { exposure }\end{array}$ & $\mathbf{2}$ & $\mathbf{1 6 . 6 7}$ \\
\hline $\begin{array}{l}\text { Patients with complete wound dehiscence (loss } \\
\text { of the graft) }\end{array}$ & $\mathbf{2}$ & $\mathbf{1 6 . 6 7}$ \\
\hline
\end{tabular}

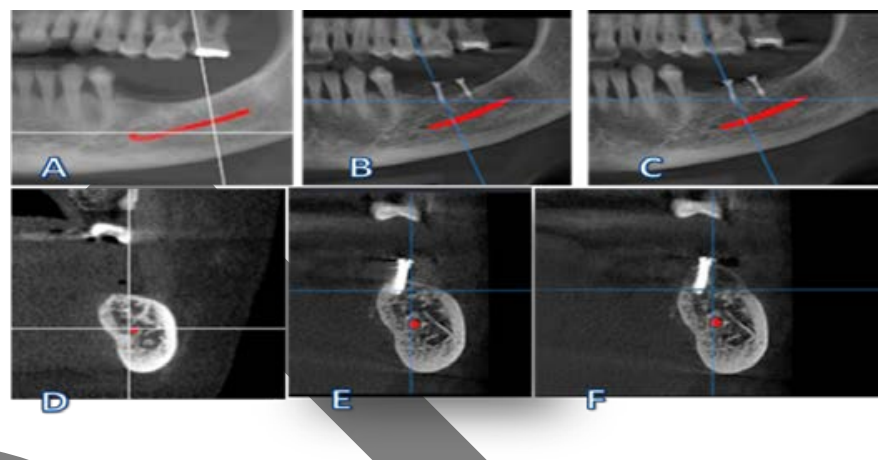

Figure (6): A) A photograph showing pre operative CBCT . B) Immediate post operative CBCT .C)CBCT after 6 months. D) A photograph showing pre operative CBCT(axial cut) . E) Immediate post operative CBCT (axial cut).F)CBCT after 6 months(axial cut).

Preoperatively, the mean vertical bone height value was $7.18 \pm 0.49 \mathrm{~mm}$ with the lowest value of $6.3 \mathrm{~mm}$ and the highest value of $7.9 \mathrm{~mm}$. While the mean bone height immediately postoperatively was $10.40 \pm 1.68$ with the lowest value of 7.0 and the highest value of 12.5 . There was statistical significant difference in bone height between the two periods $(\mathrm{p} 1<0.001)$

Six months later, the mean bone height value was $9.23 \pm 1.25$ with a minimum value of 7.0 and a maximum value of 11.1. There was statistical significant difference between the mean bone height value immediately after augmentation and six months later $(\mathrm{p} 3<0.001)$, also there was statistical significant difference between the mean bone height value preoperatively and after 6 months. (p2<0.001) (Table 2).

Table (2): Descriptive analysis of the studied cases according to post-operative BONE HEIGHT ( $n=12)$

\begin{tabular}{||c|c|c|c|c|c|c|}
\hline $\begin{array}{c}\text { Post- } \\
\text { operative } \\
\text { BONE } \\
\text { HEIGHT }\end{array}$ & $\begin{array}{c}\text { BONE } \\
\text { HEIGHT } \\
\text { PRE - OP }\end{array}$ & $\begin{array}{c}\text { BONE } \\
\text { HEIGHT } \\
\text { IMMEDIAT } \\
\text { E POST - OP }\end{array}$ & $\begin{array}{c}\text { BONE } \\
\text { HEIGHT } \\
6- \\
\text { MONTH } \\
\text { POST OP }\end{array}$ & F & p & $\begin{array}{c}\text { Partial } \\
\text { Eta } \\
\text { Square } \\
\text { d } \\
\text { Effect } \\
\text { Size })\end{array}$ \\
\hline $\begin{array}{c}\text { Min. }- \\
\text { Max }\end{array}$ & $6.3-7.9$ & $7.0-12.5$ & $7.0-11.1$ & & & \\
\hline $\begin{array}{c}\text { Mean } \\
\pm \text { SD. }\end{array}$ & $\begin{array}{c}7.18 \pm 0.4 \\
9\end{array}$ & $10.40 \pm 1.68$ & $\begin{array}{c}9.23 \pm 1.2 \\
5\end{array}$ & $\begin{array}{c}37.48 \\
*\end{array}$ & $\begin{array}{c}<0.001 \\
*\end{array}$ & $77.31 \%$ \\
\hline $\begin{array}{c}\text { Media } \\
\mathrm{n}\end{array}$ & 7.25 & 10.55 & 9.15 & & & \\
\hline Sig. & \multicolumn{2}{|c|}{$\mathrm{p} 1<0.001 *, \mathrm{p} 2<0.001 *, \mathrm{p} 3<0.001 *$} & & \\
\hline
\end{tabular}

F,P: $\mathrm{F}$ and $\mathrm{P}$ values for $\mathrm{F}$ test (ANOVA) with repeated measures for comparing between different periods

p1: p value for comparing between Pre-operative and Immediately Post-operative

p2: $p$ value for comparing between Pre-operative and after 6 months p3: p value for comparing between Immediately Post-operative and after 6 months

*: Statistically significant at $\mathrm{p} \leq 0.05$ 


\section{b. CBCT for measurement of bone density}

In the immediate post-operative phase, the mean gray density value was $270 \pm 68.92$ with the lowest value of 170 and the highest value of 392.33. In the sixth month, the mean bone density was $353.25 \pm 53.75$ with the lowest value of 190.8 and the highest value of 550. (Table 3).

Table (3): Descriptive analysis of the studied cases according to post-operative DENSITY $(n=12)$

\begin{tabular}{|c|c|c|c|c|}
\hline $\begin{array}{l}\text { Radiographice } \\
\text { assessment }\end{array}$ & $\begin{array}{l}\text { Immediate } \\
\text { Post- } \\
\text { operative }\end{array}$ & $\begin{array}{l}\text { After six } \\
\text { months Post- } \\
\text { operative }\end{array}$ & $\mathrm{p}$ & $\begin{array}{c}\text { Rate of } \\
\text { improvemen } \\
t\end{array}$ \\
\hline $\begin{array}{l}\text { Min- Max } \\
\text { Mean } \pm \text { SD } \\
\text { Median }\end{array}$ & $\begin{array}{c}170- \\
392.33 \\
270 \pm 68.9 \\
2 \\
\end{array}$ & $\begin{array}{c}190.5-550 \\
353.25 \pm 53.7 \\
5\end{array}$ & 0.00 & $30,67 \%$ \\
\hline
\end{tabular}

$\mathrm{t}, \mathrm{p}$ : $\mathrm{t}$ and $\mathrm{p}$ values for Paired t-test for comparing between immediate post-operative and after 6 post-operative

*: Statistically significant at $\mathrm{p} \leq 0.05$

\section{DISCUSSION}

Severe vertical alveolar ridge defects are 3-dimensional and are tricky to the implant surgeon. In addition, horizontal ridge defects are usually associated with the vertical defects, and they have to be restored in all dimensions for better esthetic and functional results (17).

Preoperatively, the medical status of the patients is important for proper selection of the patients to maximize the benefit from this surgery. This procedure is not an ideal choice for (uncontrolled) diabetic patients and (heavy) smokers (18).

Regarding vertical alveolar ridge resorption, it can be particularly hard to restore the vertical alveolar dimensions because of the collapse of soft tissue over the graft (19). Moreover, with vertical ridge augmentation, it is necessary to maintain a space for grafting to reduce the rate of graft resorption and permit for uniform bone healing. In the present study, we opted to use titanium mini- screws to tent the soft tissue resembling Bash Le et al., 2010 technique. Pre-operative CBCT was done for every patient. Several studies stated that using CBCT in implant surgery differs from preoperative analysis concerning definite anatomical considerations and treatment planning to postoperative evaluation (20,21). Furthermore, relatively low costs, less doses of radiation, Also, the CBCT images with relative gray density values make it a valuable alternative for computerized tomography (CT) $(22,23)$. Immediate postoperative and after 6 months CBCT was done to measure and to evaluate the changes in the bone height and density. For the bone density, estimated values in the grayscale or voxel values for the CBCT were recorded.

About the surgical procedure, under local anesthesia, access to the alveolus was preferred to be through a horizontal full thickness mid-crestal incision and releasing incision is done to enable tension-free closure. This is in accordance with le et al., 2008 (24).

Louis et al., 2008 (25), and Bash Le et al., 2010 (5), all used standard crestal incisions with vertical releasing incision and a flap with a broad base to allow maintenance of blood supply. This was different from other studies that employed the tenting of soft tissue. Marx et al., 2002 (26), used a transcutaneous submental approach and Akoush et al., 2014 used vestibular incision (27).

Alexandria Dental Journal. Volume 46 Issue 1 Section A
An average of 3-5 mm of the screws was left exposed supracrestally. According to Bash et al., 2010, these tent poles help to prohibit soft tissue contraction around the particulate graft and subsequent resorption or displacement of the grafting material is also diminished (25).

Several kinds of materials are utilized in ridge augmentation: autologous bone, xenografts, alloplastic materials and several mixtures of these materials with acceptable outcomes in terms of biocompatibility and stimulation of bone formation (28). Each bone grafting material has benefits and drawbacks. Autogenous bone grafts have osteogenic, osteoconductive, and osteoinductive properties, so they believed to be the gold standard. Nevertheless, requiring a second donor site and the associated rapid resorption are the disadvantages of this type of grafting. xenografts and allografts are obtained from other animals or humans, so they are undesirable to many patients. Also, these materials are of high cost and have the possibility of transmission of diseases. Alloplastic materials as the nanocrystalline hydroxyapatite (NanoBone $\left.{ }^{\circledR}\right)$ therefore offer another option. In the present study, Nanobone graft with PRF was chosen for the higher osteoconductive capacity $(7,29)$. Clinical trials indicated that combining the bone grafts with the growth factors in the PRF may accelerate and improve the healing process. This was supported by a study conducted by Eldibany\& Shokry, 2014 (30) who concluded that the quality and the amount of the regenerated bone was improved when using Nanobone ${ }^{\circledR} / \mathrm{PRF}$ combination. In contrast to Alrayess et al., 2016 (31), when mini plates /PRF and miniplates only were used for the treatment of mandibular fractures, there was no statistically significant difference in the bone density between the test and control groups.

In fact, PRF undergoes complete degradation within14 days, so it only has a role in the healing process particularly the angiogenesis. This is in agreement with Dohle et al., 2017(32) they conducted in vitro study in which a co-culture system of outgrowth endothelial cells (OECs) and primary osteoblasts (pOBs) was mixed with injectable PRF and was cultivated. Formation of lumina and microvessel-like structures has been shown histologically in the PRF/coculture complexes after 7 days along with a higher countenance of the proangiogenic factor (VEGF). So, PRF might positively affect the healing process, in specific, angiogenesis.

Guided bone regeneration with resorbable barrier membranes can preclude the incursion of the undesirable cells from the connective tissue into the bony defects and enhance bone formation. They also completely metabolized after 6 months. Similar studies of, Dahlin et al., 1990 (33) stated that a resorbable membrane can block the ingrowth of the soft tissue into the bone defects. So, the bilayer hyprosorb ${ }^{\circledR}$ membrane was the barrier membrane of choice for the present study. It was fixed in the lingual side of the defect with its rough surface toward the bone and stretched out with mini-tacks to completely immobilize the graft material, this is what is called sausage technique, Istvan Urban, 2011 (34).

This was dissimilar to other studies which proposed that non resorbable membranes are more reliable and retain the stability of the grafting materials for a long period (35). Also, some studies concluded that the intact periosteum acts as a mechanical barrier and a source of osteogenic components, 
thus it is a good membrane that contributes to new bone formation (36).

In the GBR procedure, perforation (decortication) of the cortical bone layer has been promoted (37), as it was assumed that this increases the wound vascularity with the release of growth factors and cells with angiogenic and osteogenic potential. In agreement with Delloye et al., (38) they found that there was increase in the amount of the newly formed with decortication in comparison with a nonperforated cortical bone.

Nevertheless, some studies with adverse results were also stated that cortical perforation did not improve the amount of bone formation in rabbits $(39,40)$.

In the present study, wound dehiscence occurred in 4 cases. This occurred when the exposed length of the screw was $\geq$ $5 \mathrm{~mm}$. it was supposed that this was not tolerated by the expanded soft tissue matrix or causing more tension on the soft tissue together with the muscle action. This is in coincidence with Louis et al., 2008 (25) who noticed a high incidence of wound dehiscence with using titanium mesh to tent the mucoperiosteum. The sharp, small head of the miniscrews also may be a causative factor. Wound dehiscence and screw head exposures were treated with conservative eare with maintenance of the oral hygiene and oral rinse during the 6-month healing period.

"Tent pole" grafting technique was performed with the mean preoperative bone hight was7.18 $\pm 0.49 \mathrm{~mm}$ with the lowest value of $6.3 \mathrm{~mm}$ and the highest value of $7.9 \mathrm{~mm}$. The mean bone height after 6 months was9.23 \pm 1.25 with the lowest value of $7 \mathrm{~mm}$ and the highest value of $11.1 \mathrm{~mm}$. This difference was statistically significant ( $p$-value $\leq 0.05$ ).

Our results are consistent with the study conducted by Bash Le et al., 2010, using mineralized allograft with autogenous particulate graft around titanium screws for tenting the soft tissue matrix and the mean vertical augmentation was 9.7 mm. Wound dehiscence was occurred in two patients causing loss of the graft and a secondary grafting was required. Second stage grafting procedures were also needed for five cases to attain ideal ridge height before implant placement (5).

Akoush et al., 2014 (27) performed a study for evaluation of the "Tent Pole" grafting technique for vertical alveolar ridge augmentation using dental implants. There was no new bone induced at both mesial and distal surfaces of the implants. However, there was new bone induced at both buccal and lingual surfaces of the implants.

The mean bone density was measured immediate postoperatively, its value was $270 \pm 68.92$. After 6 months, the mean bone density values were $353.25 \pm 53.75$. The difference between the two periods was statistically significant (p-value $<0.001)$.

The results are reinforced by the study conducted by Eldibany\& Shokry 2014 (30), the results of their study showed that the Nanobone/ PRF mixture enhanced the healing of the bone and improved the quality and the amount of the new bone. The rate of increase in bone density was $22 \%$ after 6 months and continued to be $50 \%$ after 9 months. Furthermore, according to these findings, there was a statistically significant difference in bone height and density after vertical ridge augmentation, so we reject the null hypothesis of this study.

\section{CONCLUSION}

From the results of this study, the screw tent -pole grafting technique with guided bone regeneration is a technique of high reliability in restoring mandibular vertical bone loss.

\section{The authors declare that they have no conflicts of interest.}

\section{REFERENCES}

1. Carlsson L, Röstlund T, Albrektsson B, Albrektsson T, Brånemark PI. Osseointegration of titanium implants. Acta Orthop Scand. 1986;57:285-9.

2. Chiapasco M, Zaniboni M, Boisco M. Augmentation procedures for the rehabilitation of deficient edentulous ridges with oral implants. Clin Oral Implants Res. 2006;17:136-59.

3. Rocchietta I, Fontana F, Simion M. Clinical outcomes of vertical bone augmentation to enable dental implant placement: a systematic review. J Clin Periodontol. 2008;35:203-15.

4. Draenert FG, Huetzen D, Neff A, Mueller WE. Vertical bone augmentation procedures: Basics and techniques in dental implantology. J Biomed Mater Res A. 2013; 102:1605-13.

5. Le B, Rohrer MD, Prasad HS. Screw “tent-pole” grafting technique for reconstruction of large vertical alveolar ridge defects using human mineralized allograft for implant site preparation. J Oral Maxillofac Surg. 2010;68:428-35.

6. Gomes KU, Carlini JL, Biron C, Rapoport A, Dedivitis RA. Use of allogeneic bone graft in maxillary reconstruction for installation of dental implants. J Oral Maxillofac Surg.2008;66:2335-8.

7. Gerike $\mathrm{W}$, Bienengräber V, Henkel KO, Bayerlein T, Proff P, Gedrange T, et al. The manufacture of synthetic non-sintered and degradable bone grafting substitutes. Folia Morphol (Warsz). 2006;65:54-5.

Shivashankar VY, Johns DA, Vidyanath S, Sam G. Combination of platelet rich fibrin, hydroxyapatite and PRF membrane in the management of large inflammatory periapical lesion. J Conserv Dent. 2013;16:261-4.

9. Del Corso M, Toffler M, Dohan Ehrenfest DM. Use of an autologous leukocyte and platelet-rich fibrin (L-PRF) membrane in post-avulsion sites: an overview of Choukroun’s PRF. J Implant Adv Clin Dent. 2010;1:27-35.

10. Simion M, Trisi P, Piattelli A. Vertical ridge augmentation using a membrane technique associated with osseointegrated implants. Int $\mathrm{J}$ Periodontics Restorative Dent. 1994;14:496-511.

11. Lindfors LT, Tervonen EA, Sándor GK, Ylikontiola LP. Guided bone regeneration using a titanium-reinforced ePTFE membrane and particulate autogenous bone: the effect of smoking and membrane exposure. Oral Surg Oral Med Oral Pathol Oral Radiol Endod. 2010;109:825-30.

12. Abd El Raouf M, Kobayashi MF, AbdEl-Aal ABM, Zhang Y, Miron RJ. Novel Bioabsorbable Bovine Derived Atelo-Collagen Type I Membrane: characterization into Host Tissues. Periodon Prosthodon. 2017;3:1-6. 
13. Kirkpatrick LA, Feeney BC. A simple guide to IBM SPSS: for version 20.0. $12^{\text {th }}$ ed. USA. Wadsworth cengage learning; 2012.

14. Porter JA, Von Fraunhofer JA. Success or failure of dental implants? A literature review with treatment considerations. Gen Dent. 2005;53:423-32; quiz 433, 446.

15. Good M, Stiller C, Zauszniewski JA, Anderson GC, Stanton-Hicks M, Grass JA. Sensation and distress of pain scales: reliability, validity, and sensitivity. J Nurs Meas.2001;9:219-38.

16. Seidel HM BJ, Dains JE, Benedict GW. Heart and blood vessels. In: Schrefer S (ed). Mosby's Guide to Physical Examination. $3^{\text {rd }}$ ed. St. Louis: Mosby; 1995.

17. Tan WL, Wong TL, Wong MC, Lang NP. A systematic review of post-extractional alveolar hard and soft tissue dimensional changes in humans. Clin Oral Implants Res. 2012;23:1-21.

18. Levin L, Schwartz-Arad D. The Effect of Cigarette Smoking on Dental Implants and Related Surgery. Implant Dent. 2005;14:357-61.

19. D’Souza D. Residual Ridge Resorption - Revisited. In: Virdi M (ed). Oral Health Care - Prosthodontics, Periodontology, Biology, Research and Systemic Conditions. Intech; 2012. P. 953-78. Available at: https://www.intechopen.com

20. Cassetta M, Sofan AA, Altieri F, Barbato E. Evaluation of alveolar cortical bone thickness and density for orthodontic mini-implant placement. J Clin Exp Dent. 2013;5:e245-52.

21. Bornstein MM, Scarfe WC, Vaughn VM, Jacobs R. Cone beam computed tomography in implant dentistry: a systematic review focusing on guidelines, indications, and radiation dose risks. Int $\mathrm{J}$ Oral Maxillofac Implants. 2014;29:55-77.

22. Pedroso LA, Garcia RR, Leles JL, Leles CR, Silva MA. Impact of cone-beam computed tomography on implant planning and on prediction of implant size. Braz Oral Res. 2014;28:46-53.

23. Chasioti E, Sayed M, Drew H. Novel techniques with the aid of a staged CBCT guided surgical protocol. Case Rep Dent 2015;2015:439706.

24. Le B, Burstein J, Sedghizadeh PP. Cortical tenting grafting technique in the severely atrophic alveolar ridge for implant site preparation. Implant Dent. 2008;17:40-50.

25. Louis PJ, Gutta R, Said-Al-Naief N, Bartolucci AA. Reconstruction of the maxilla and mandible with particulate bone graft and titanium mesh for implant placement. J Oral Maxillofac Surg. 2008;66:235-45.

26. Marx RE, Shellenberger T, Wimsatt J, Correa P. Severely resorbed mandible: Predictable reconstruction with soft tissue matrix expansion (tent pole) grafts. J Oral Maxillofac Surg. 2002;60:878-88.

27. Akoush YH, Hakam MM, Al farmawy MI. Evaluation of "Tent Pole" grafting technique for vertical alveolar ridge augmentation with the use of rhBMP-2. M.Sc. Thesis. Faculty of Dentistry, Cairo University. 2014.

28. Hoexter DL. Bone regeneration graft materials. J Oral Implantol. 2002;28:290-4.

29. Dietze S, Bayerlein T, Proff P, Hoffmann A, Gedrange T. The ultrastructure and processing properties of Straumann
Bone Ceramic ${ }^{\circledR}$ and NanoBone ${ }^{\circledR}$. Folia Morphol (Warsz). 2006;65:63-5.

30. Eldibany RM, Shokry MM.The effect of Nanobone ${ }^{\circledR}$ in combination with platelet rich fibrin on bone regeneration following enucleation of large mandibular cysts. Tanta Dent J. 2014;11:100-8.

31. Al Rayess AM, El Dibany MM, Melek LN. Clinical and radiographic study of healing of mandibular fractures using plasma rich fibrin membrane with miniplate fixation. Alex Dent J. 2018;43:41-7.

32. Dohle E, El Bagdadi K, Sader R, Choukroun J, James Kirkpatrick C, Ghanaati S. Platelet-rich fibrin-based matrices to improve angiogenesis in an in vitro co-culture model for bone tissue engineering. J Tissue Eng Regen Med. 2018;12:598-610.

33. Dahlin C, Gottlow J, Linde A, Nyman S. Healing of maxillary and mandibular bone defects using a membrane technique. An experimental study in monkeys. Scand J Plast Reconstr Surg Hand Surg. 1990;24:13-9.

34. Urban IA, Nagursky H, Lozada JL. Hori-zontal ridge augmentation with a re-sorbable membrane and particulated autogenous bone with or without anor-ganic bovine bonederived mineral: A prospective case series in 22 patients. Int J Oral Maxillofac Implants. 2011;26:404-14.

35. Simion M, Fontana F, Rasperini G, Maiorana C. Vertical ridge augmentation by expanded-polytetrafluoroethylene membrane and a combination of intraoral autogenous bone graft and deproteinized anorganic bovine bone (BioOss). Clin Oral Implants Res. 2007;18:620-9.

36. Yang JW, Park HJ, Yoo KH, Chung K, Jung S, Oh HK, et al. A comparison study between periosteum and resorbable collagen membrane on iliac block bone graft resorption in the rabbit calvarium. Head Face Med 2014;10:15.

37. Schmid J, Wallkamm B, Hämmerle CH, Gogolewski S, Lang NP. The significance of angiogenesis in guided bone regeneration. A case report of a rabbit experiment. Clin Oral Implants Res.1997;8:244-8.

38. Delloye C, Simon P, Nyssen-Behets C, Banse X, Bresler F, Schmitt D. Perforations of cortical bone allografts improve their incorporation. Clin Orthop Relat Res. 2002;396:240-7.

39. Slotte C, Lundgren D. Impact of cortical perforations of contiguous donor bone in a guided bone augmentation procedure: an experimental study in the rabbit skull. Clin Implant Dent Relat Res. 2002;4:1-10.

40. Barbosa DZ, de Assis WF, Shirato FB, Moura CC, Silva CJ, Dechichi P. Autogenous bone graft with or without perforation of the receptor bed: histologic study in rabbit calvaria. Int J Oral Maxillofac Implants. 2009;24:463-8. 